\title{
The Moderating Effect of Food Safety Knowledge on Organic Food Purchase Intention in a New Normal
}

\author{
Muhammad Safuan Abdul Latip ${ }^{1,2 *}$, Farhana Tahmida Newaz², Mohamad Amiruddin \\ Mohamad', Siti Aisyah Tumin ${ }^{3}$, Nur Farihin Abdul Rahman ${ }^{3}$ and Ismayaza Noh ${ }^{4}$ \\ ${ }^{1}$ Faculty of Hotel and Tourism Management, Universiti Teknologi MARA Cawangan Terengganu, Kampus \\ Dungun, 23000 Dungun Terengganu, Malaysia \\ ${ }^{2}$ Graduate School of Business, Universiti Tun Abdul Razak, 50400 Kuala Lumpur, Malaysia \\ ${ }^{3}$ Faculty of Hotel and Tourism Management, Universiti Teknologi MARA, Cawangan Pulau Pinang, Kampus \\ Permatang Pauh, 13500 Permatang Pauh, Pulau Pinang, Malaysia \\ ${ }^{4}$ Faculty of Hotel and Tourism Management, Universiti Teknologi MARA, Cawangan Selangor, Kampus Puncak \\ Alam, 42300 Puncak Alam, Selangor, Malaysia
}

\begin{abstract}
The emergence of a 'new normal' life caused by pandemic Coronavirus Disease (COVID-19) leads to consumer perception and business practices changes. However, there is limited data on the current market demand and condition on consumer purchase intention of organic food associated with food safety knowledge. Thus, this study aimed to examine consumer perception toward organic food in a new normal life. A total of 330 valid responses were received for analysis using Structural Equation Modelling (SEM) and PROCESS. The data were collected in Malaysia using an online questionnaire mainly because of physical distances and Movement Control Order (MCO). The finding revealed that personal attitude, perceived social pressure, and perceived autonomy influence organic food purchase intention in a new normal life. However, it is not perceived as green trust. Besides, food safety knowledge significantly moderates the relationship between personal attitudes toward organic food purchase intention. The finding is valuable for current

ARTICLE INFO

Article history:

Received: 14 April 2021

Accepted: 19 August 2021

Published: 03 December 2021

DOI: https://doi.org/10.47836/pjssh.29.4.10

E-mail addresses:

safuanlatip@uitm.edu.my (Muhammad Safuan Abdul Latip)

farhana@unirazak.edu.my (Farhana Tahmida Newaz)

amiruddinmohamad@uitm.edu.my (Mohamad Amiruddin Mohamad)

aisyahtumin@uitm.edu.my (Siti Aisyah Tumin)

nurfarihinars@gmail.com (Nur Farihin Abdul Rahman)

ismay147@uitm.edu.my (Ismayaza Noh)

producers, marketers, and the government body to understand the changes in consumer purchase intention in a new normal life and assist future planning and operationalising to protect, develop and maintain the organic food industry.

Keywords: COVID-19, food safety, individual green consideration, Malaysia, organic food, purchase intention
\end{abstract}

* Corresponding author 


\section{INTRODUCTION}

The COVID-19 was declared by the World Health Organisation (WHO) as a global pandemic. The pandemic affects the business and society's life, which leads to the emergence of a new normal life to break the chain of infection. However, the new normal life simultaneously causes changes in consumer purchase intention, decision and business practices due to safety reasons, as the virus can be transmitted between humans and other surfaces (Sajed \& Amgain, 2020). Thus, addressing consumer perception in a new normal life is crucial to access the latest market condition and demand. Indeed, the study is fruitful for market development and planning among the market players.

Consumers perceive organic food as safe, clean, and healthy compared to conventional food (Latip et al., 2020a; Somasundram et al., 2016). However, previous studies mainly focus on environmental sustainability and consumer intention to purchase organic food. Therefore, a limited study was conducted to understand consumer perception and response to the COVID-19 pandemic concerning organic food purchase. The intersecting link for carrying the present study is a new normal life is because of concern on the food safety and health during the pandemic as the virus can be easily transmitted between humans and other surfaces (Latip et al., 2020b; Sajed \& Amgain, 2020). Indeed, the present study is critical for developing and future planning of the local organic market as people adjust to the new normal life and limited finding available leading to a new gap. Moreover, uncertainty perceived by the consumer on the factors affecting consumer intention to purchase organic food in new normal life is undeniable (Latip et al., 2020b). Thus, hindrance an effective communication and segmenting consumers in the market to tailor with the new normal life of COVID-19.

Previous studies highlighted consumer concern for a safe food supply, especially in a country with food safety issues and health that are potentially caused by safety incidents and food-related diseases (Latip et al., 2020b; Prentice et al., 2019; Wang et al., 2018). Moreover, food safety becomes a concern expressed largely by Asian countries' (Latip et al., 2020b; Putten \& Nair, 2019). Given the current global health crisis of COVID-19 that impact every aspect of life, including food safety concern, key players in the organic food industry should understand factors that influence consumers intention to purchase organic food. COVID-19 has influenced consumers' perception of health and risk that impact and boost their belief towards food organic consumption (Hassen et al., 2020). According to Latip et al. (2020b), consumers' attitudes and trust towards organic food relate to safety, hygiene and health during worldwide health crises affected by food safety knowledge.

Furthermore, a recent study acknowledges the food safety knowledge relationship towards consumer perceived social pressure and autonomy that can influence individual decision making in organic food purchase intention (Latip et al., 2021). Adawiyah et al. (2021) further 
elaborate that relevant knowledge related to organic food can enhance consumers' preferences and awareness of organic food choices. Accordingly, through knowledge and trust, food safety can be minimised and potentially influences consumer purchase intention and decision (Ha et al., 2018). In addition, Sajed and Amgain (2020) stated that the COVID-19 pandemic affects consumers' perception of the importance of physical health and minimises the risk of the disease. Thus, the previous studies profoundly address how knowledge may potentially affect consumer purchase intention (Adawiyah et al., 2021; Latip et al., 2020b, 2021). Henceforth, this study will emphasise the moderating effect of food safety knowledge towards organic food purchase intention in a new normal during pandemic COVID-19, as when healthrelated issues such as COVID-19 arise, the consumer will be very selective on their food consumption to maintain good health (Latip et al., 2020b). Indeed, a recent study estimated that two out of the third proportion of consumers had increased their intention to purchase green food due to the health concern towards COVID-19 (Qi et al., 2020) and to increase their immune system during the time of COVID-19 (Chaturvedi et al., 2021). Therefore, a recent study in a new normal life is essential as consumers' perception, judgement and decision of organic food and food safety could change. However, there are limited findings available in a local setting to assist the market players in planning and strategising the business.
Accordingly, this study is expected to contribute both from a theoretical and practical perspective. From a theoretical perspective, the finding can provide a better explanation and understanding to scholarly researchers on what factors in a new normal life can potentially affect consumer purchase intention and decision, which lead to new research direction. Furthermore, the study's outcome is expected to benefit government agencies and business entities from a practical perspective. It can be used to plan and operationalise strategies to govern and develop the organic food market.

Moreover, the finding is critical to respond to the agriculture industry's challenges locally. It is important to address as the organic market in Malaysia estimation is valued only at 2.5 million dollars, representing $0.0221 \%$ of the total Asian market value (Euromonitor International, 2017, as cited in Jaafar et al., 2020). However, the agriculture and the organic sector are predicted to contribute significantly to the country's GDP, as mentioned by the Agriculture and Agro-based Industry Minister of Malaysia (Babulal \& Krishnan, 2020). Thus, study related to organic food purchase from a consumer perspective is critical to be conducted regularly to understand the consumer intention and demand. Moreover, the gaps between consumer perception and product delivery can be decreased based on current market conditions and demand. Simultaneously, flourish the organic food market and the local economy overall. Thus, this study aims to answer the following research questions: 
1. Will the new normal life of pandemic COVID-19 influence consumer purchase intention towards organic food?

2. Will the knowledge of food safety moderate consumer purchase intention towards organic food?

\section{LITERATURE REVIEW}

\section{Underline Theory and Model}

The Theory of Planned Behaviour (TPB) is considered the most relevant conceptual construct model used to predict a human purpose to carry out different types of action. TPB focused on explaining and exploring the three exogenous variables, namely attitude, subjective norm, and perceived behaviour control (PBC), as fundamental in predicting the food product behaviour (Latip et al., 2020b). Moreover, the TPB applies a philosophy of behavioural nature to foresee and explain human behaviour in terms of external forces (social pressure), available opportunities, and obstacles, to justify the possible effects of the action to be performed (Ajzen, 1991; Latip et al., 2020b). Thus, this behaviour can be predicted through intention with more accuracy when it is influenced by other factors (Ajzen, 1991).

Furthermore, the model could be extended by including the domain factors to enhance the TPB model in organic food studies (Latip et al., 2020a). Thus, perceived green trust and food safety knowledge were added in this study. Food safety has rising concern among consumers influenced by other environmental and health issues; hence, this factor potentially influences intention to purchase, which will affect a real (Latip et al., 2021; Putten \& Nair, 2019).

\section{Relationship of Personal Attitude, Perceived Social Pressure, Perceived Green Trust, and Perceived Autonomy}

Personal Attitude. TPB's attitude acts as a significant antecedent to behavioural intention, defined as the degree of favourable or unfavourable consideration of the behavioural studied (Ajzen, 1991). Few factors help shape the personal attitude, including personal values, personalities, experience, knowledge, and awareness (Xie et al., 2015). Indeed, with a restriction of information and understanding of organic food, the intention to purchase organic food is decreased, with several factors influencing consumers' preferences and attitudes (Xie et al., 2015). However, a positive attitude towards a certain action increases the desire to carry out that particular behaviour or action (Ajzen, 1991). The finding agrees with those other researchers whereby consumers' positive attitude significantly impacts the purchase intention of organic food products (Bai et al., 2019; Ham et al., 2018; Lian, 2017). However, due to the global health pandemic, consumers are very concerned about their health and food choices (Latip et al., 2020b; Xie et al., 2020). Indeed, a recent study highlighted the potential effect of personal consumer attitude toward a health-related crisis that influences consumer decision and trust in organic food purchase intention due to underline personal perception risk (Latip 
et al., 2020b). Thus, studying the impact of new normal life in shaping the individual attitude towards organic food products' purchase intention is crucial.

Perceived Social Pressure. Perceived social pressure describe as personal feelings influenced by the pressure from the surroundings, including the society, which may affect their judgement to engage or not to engage in that particular action (Latip et al., 2020a; Madden et al., 1992). The previous study reported that social pressure influences individual purchase intention on organic food and directly influences the purchase attitude (Scalco et al., 2017). This result indicates the impact of perceived social pressure appeared to be overwhelmed by the personal attitude or consideration (Ajzen, 1991). Bai et al. (2019) and Latip et al. (2020b) found a significant relationship between subjective norms and intention to buy organic food. Besides, further investigation of perceived social pressure is critical as it is correlated in shaping purchase attitude and purchase behaviour as the pandemic affects society overall (Latip et al., 2020b). Thus, in this study, the existence of COVID-19 and new life practising in the community were investigated.

Perceived Autonomy. Perceived autonomy is closely related to psychological behaviour that explains individuals' ability to decide and manage their own lives. This behavioural control plays a vital role in self-determinant that makes them feel that they have control to perform or not perform that particular action. The earlier study by Ajzen (1991) states that this behaviour is shaped by various factors, including experience and knowledge of organic food. Ham et al. (2018) discuss the two elements involved in influencing individual behaviour control in intention to purchase organic food, which is an intrinsic factor (individual judgement on knowledge and capacity to perform specific behaviour) and extrinsic factors (the degree to which individuals interpret with external forces including time and income). Therefore, the higher behaviour control individuals have, the more likely they are to purchase organic food. Aertsens et al. (2009) review stated that the environmental problem plays an important role in strengthening individual behaviour. It may be relevant organic food consumption since the price premium people confront may be a purchase barrier and clash with their desire to buy environmentally friendly products.

Moreover, previous studies have pointed out that perceived autonomy significantly influences intention to purchase organic food, especially during conflict and world pandemics (Latip et al., 2020b, 2021). In this study, a new norm practice has affected consumer behaviour and changed their perception of organic food. The researchers also looked into the new normal life in assisting individual autonomy to buy organic food. Different forces surround the consumer due to Movement Control Order (MCO), leading to the slowdown of economic growth. 
Perceived Green Trust. Trust is an individual's tendency to be a direct precursor that influences purchase attitude and intention towards organic food (Bai et al., 2019). As Latip et al. (2020a) proposed in this current study green personal trust focuses primarily on the individual viewpoint rather than system trust (suppliers' external aspect of trust, marketers' organisations). Green personal trust describes an individual's willingness to rely on the product or service based on confidence in its experience, reputation, efficiency and environmental protection capability (Bai et al., 2019; Latip et al., 2020a). The study in China found a direct relationship between trustworthiness and purchase intention of organic food. However, there is no influence on purchase attitude and behaviour (Bai et al., 2019). This scenario may influence by food safety issues, food authenticity issues, food scandal issues, and other critical issues. Besides, health and risk considerations, especially during the pandemic of COVID-19, might give a different insight because the consumer theoretically has a high tendency to look for a safe and healthy product to consume in a new normal life based on perceived personal trust (Latip et al., 2020b; Xie et al., 2020) Trust, therefore, plays an important role in shaping consumer purchase attitude and purchase intention. Thus, it is essential to investigate the perceived green trust in the context of this study to understand better the consumer's underlying decision in a new normal life. The proposed hypothesis is as follow:
H1: Personal attitude influences organic food purchase intention in a new normal life

H2: Perceived social pressure influences organic food purchase intention in a new normal life

H3: Perceived green trust influences organic food purchase intention in a new normal life

H4: Perceived autonomy influences organic food purchase intention in a new normal life

\section{Organic Food Purchase Intention}

The surge demands of customers towards organic food have been steadily increasing due to the growing awareness regarding the benefits of organic food consumption. Consumers' positive attitude regarding organic food consumption has significantly influenced their intention to purchase them (Latip et al., 2020b). Moreover, further reasons such as increasing knowledge among consumers pertaining to health concerns have driven them to choose organic food. The dissemination of news through social media and other media platforms on food scandals and warning the dangers of conventional foods have influenced consumers to consider organic food (Rieger et al., 2016).

On top of that, social pressure and the degree of individual autonomy also initiated consumers' intention to purchase organic food. Social pressure happens when individuals want to positively impact their social identity to appear socially desirable to society (Latip et al., 2020b). Subsequently, 
this shapes the behavioural intention of an individual (Yzer, 2017), as previous studies found a significant relationship between social pressure and subjective norm toward buying intention of organic food (Ham et al., 2018; Qi \& Ploeger, 2019). The higher degree of autonomy an individual has to decide, the more likely they will have the intention to purchase organic food (Latip et al., 2020b) because intention starts with the individual's willingness to buy organic foods.

Besides that, consumers' trust towards green products can influence consumers' intention to purchase organic food. According to Giampietri et al. (2018), trust plays an important role in consumers' decision-making on food purchases. The positive attitude derived from trust leads to the positive impact of consumer purchase decisions on green products (Baktash \& Talib, 2019).

\section{Moderating Effect of Food Safety Knowledge}

Food safety has become a key factor in the food industry, as consumers are now looking for safer and healthier food to eat. According to Fraser (2001), one of the main factors that influence consumers is that consumers are more concerned about their health and safety (Shaw, 2004). Subsequently, this has raised awareness amongst consumers to get more knowledge on food safety. Teng et al. (2011) stated that consumers are more concerned about getting information and knowledge regarding a chemical used in food production. The researchers also suggested that this factor should determine the consumers' intention to purchase organic or green food. It is parallel with the recent study whereby the information consumers get through media platforms regarding food scandals and dangers of conventional food influenced them to choose organic food (Rieger et al., 2016).

Indeed, when a person knows food safety, they have more control over their decision-making, especially during the pandemic (Latip et al., 2020b).

Furthermore, food safety knowledge significantly influences personal attitude, social pressure, and autonomy, potentially influencing individual decisions regarding organic food purchase intention (Latip et al., 2021). It is also supported by the previous study as knowledge related to the product can enhance consumer preferences and awareness towards product choices (Adawiyah et al., 2021). Thus, knowledge potentially strengthens or weakens the relationship toward the organic food purchase intention as concern on food safety can be minimised, potentially influencing purchase decision through knowledge (Ha et al., 2018). Thus, the potential moderating effect of food safety knowledge regard to organic food purchase intention is worth being investigated as organic food is perceived to be safe and healthy, which important indicator in the pandemic COVID-19 scenario to ensure a fit and healthy body to reduce potential infection (Latip et al., 2021; Sajed \& Amgain, 2020). 
Indeed, as the pandemic COVID-19 is associated with individual health and safety, food safety knowledge significantly influences individual green consideration regarding organic food, including attitude, social pressure, autonomy, and green trust (Latip et al., 2020b). Consequently, this study explores the roles of knowledge from a food safety perspective as a moderating variable towards consumers purchase intention of organic food. Therefore, the hypothesis was postulated as follows:

H5: The positive effect of personal attitude and organic food purchase intention is stronger with food safety knowledge

H6: The positive effect of perceived social pressure and organic food purchase intention is stronger with food safety knowledge

H7: The positive effect of perceived green trust and organic food purchase intention is stronger with food safety knowledge
H8: The positive effect of perceived autonomy and organic food purchase intention is stronger with food safety knowledge

\section{METHODOLOGY}

This study is a quantitative study that uses primary data through an administered questionnaire because of the large population and to achieve the research objective - the causal study applied through a non-contrived approach and a cross-sectional method. The data were collected in a new normal life of COVID-19. The study's target population is Malaysian residence aged 15 years and above with no other controlled demographic profile of respondents. The study aims to identify factors influencing organic food purchase intention; thus, the respondents can be organic or non-organic users. All respondents were agreed to participate in the survey voluntarily. For Structural Equation Modelling (SEM) analysis, on each 1 item, tested ten numbers of respondents were

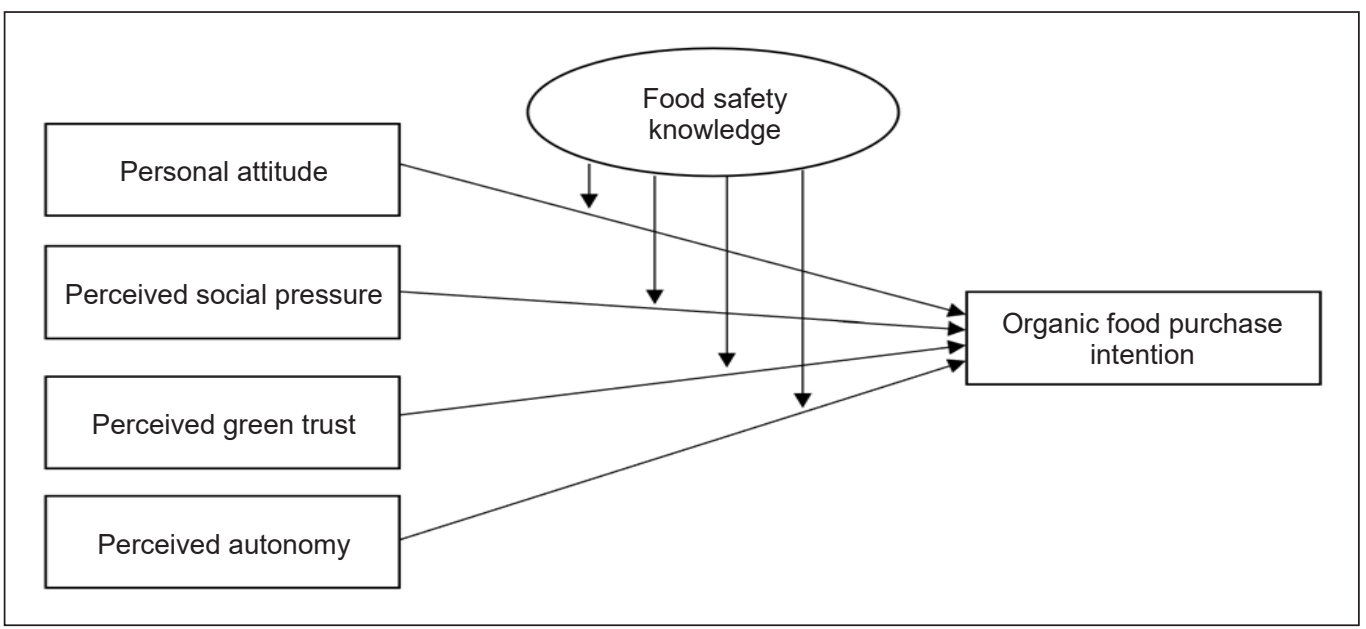

Figure 1. Conceptual framework 
needed (Hair et al., 2010). Therefore, as the study instrument consists of 24 items, a total of 240 minimum samples is required. The instruments were adopted and adapted from previous empirical studies related to a green purchase (Correa et al., 2017; Junior et al., 2019; Lian \& Yoong, 2019; Putten \& Nair, 2019). It is also supported by Latip et al. (2020b).

Moreover, five Likert scale measurement was used in the study because the respondents will be incapable of defining themselves on the scale if the scale is divided into too many or too few points (Briggs et al., 2012). Finally, the research instrument was distributed in the English language.

The data were collected using convenience sampling using an online platform because of the COVID-19 pandemic and physical distance concerns (Sajed \& Amgain, 2020). Thus, direct contact needs to be avoided. The survey was shared and sent to online groups through social platforms, mainly WhatsApp. There was a total of 330 valid responses after removing outliers to ensure an accurate finding. Thus, a minimum sample size required by the study is achieved.

The Analysis of Moment Structure (AMOS), Statistical Package for Social Science (SPSS), and PROCESS by Andrew F. Hayes analysis was used for data analysis (Hayes, 2013). Data had been screened and cleaned to ensure clean data through minimum and maximum analysis. Notably, the normality of data was confirmed as the skewness and kurtosis presented in table 2 scored between +1 and -1 (Hair et al., 2017), and necessary outliers were removed to ensure a good and reliable finding.

Common method bias was performed using Herman's Single Factor test, and the total variance for one-factor scores was 46.004. Therefore, it confirmed no issue of method bias as the variance score is less than 50.00 (Eichhorn, 2014).

\section{Descriptive Analysis}

The analysis of respondents' demographic profiles shows that female respondents $(67.3 \%)$ outnumbered male respondents (32.7\%). Meanwhile, most of the respondents were aged between 21 to 30 years old (58.5\%), followed by $21.8 \%$ aged between 31 to 40 years old. Furthermore, based on the respondent's academic background, $45.5 \%$ of respondents with academic background of bachelor's degrees, followed by a master's degree $(30.0 \%)$ and $19.7 \%$ with diploma certificates. Thus, it can be concluded that most of the respondents have a good educational background and knowledge. Meanwhile, most of the respondents had an income level below RM1,000 (33.6\%), followed by $17.3 \%$ with a monthly income of RM2,001 to RM3,000), and lastly, 14.2\% of respondents earn a monthly income of RM5,000 and above.

The descriptive analysis of the research instrument was conducted and presented in Table 1. Based on the average mean score, it can be concluded that the respondent has good food safety knowledge $(M=3.90)$, personal attitude $(M=3.64)$, perceived autonomy $(\mathrm{M}=3.51)$, and perceived green trust $(M=3.78)$. Meanwhile, respondents 
Table 1

Descriptive analysis of research instruments

\begin{tabular}{llll}
\hline No & Items & Mean & Average mean \\
\hline K1 & Knowledgeable about food safety & 4.05 & \\
K2 & Knowledgeable on food safety certificates & 3.67 & 3.90 \\
K3 & Knowledgeable on food selection to reduce potential foodborne illness & 3.90 & \\
K4 & Good food safety knowledge & 3.96 & \\
A1 & Organic food purchase is important & 3.73 & \\
A2 & Organic food purchase is beneficial & 3.76 & \\
A3 & Purchase organic food is a wise decision & 3.68 & \multirow{2}{*}{3.64} \\
A4 & Organic food consumption is important for everyone & 3.71 & \\
A5 & Organic food consumption reduces the potential risk of infection & 3.31 & \\
A6 & Organic food is a better choice during the pandemic & 3.62 & \\
S1 & Family influence during the pandemic & 3.25 & \\
S2 & Friends influence during the pandemic & 3.15 & 3.19 \\
S3 & Influence of important people to individual & 3.24 & \\
S4 & Influences from social media connections & 3.10 & \\
AU1 & Have time to purchase organic food & 3.50 & \multirow{2}{*}{3.51} \\
AU2 & Willingness to purchase organic food & 3.52 & \\
AU3 & Have autonomy to purchase organic food & 3.50 & \\
T1 & Reliable food safety reputation of organic food & 3.81 & \\
T2 & Trustworthy claims of organic food & 3.78 & \multirow{2}{*}{3.78} \\
T3 & Food safety expectation of organic food & 3.79 & \\
T4 & Food safety promises of organic food & 3.76 & \\
T5 & Trust on food producers claim & 3.74 & \\
I1 & Will buy organic food for family safety & 3.35 & \multirow{2}{*}{3.38} \\
I2 & Intention to purchase organic food & 3.40 & \\
\hline & & &
\end{tabular}

have a moderate influence of the social pressure $(\mathrm{M}=3.19)$ and moderate to high intention to purchase organic food during in new normal life COVID-19 (M=3.38).

\section{Confirmatory Factor Analysis}

The Confirmatory Factor Analysis (CFA) was conducted to measure the model to verify each item's psychometric characteristics in the instrument.

The CFA results are shown in Figure 2. The analysis shows that all loading factors of the items scored 0.60 and above, indicating an excellent psychometric characteristic for each item (Awang et al., 2018). The model fitness indicates the scored CMIN/ DF (the minimum discrepancy) of 2.212. Meanwhile, the comparative fix index CFI score of 0.957 is considered a good fit for the model. The model score of 0.061 with a confidence interval of the root mean square error of approximation (RMSEA) indicates a good fitness of the model because it shows a close fit of the model with the level of 


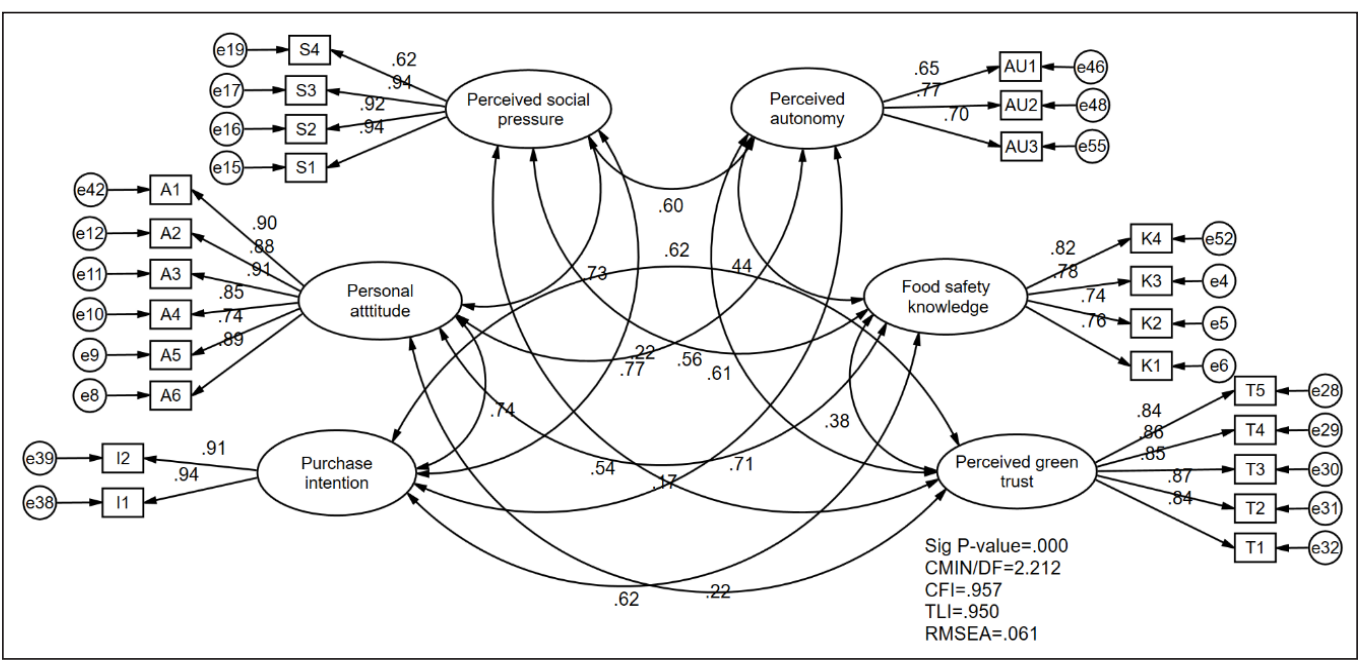

Figure 2. CFA analysis

freedom (Awang et al., 2018). Thus, the model achieved good model fitness.

\section{Reliability and Validity Analysis}

The composite reliability (CR) and average variance extracted (AVE) in Table 2 were used to measure the construct's reliability and validation. As shown in Table 2, all CR scored above 0.60, and AVE scored above 0.50 . The figures indicate the data achieved a good convergent validity as over half of the item variances can be represented by the construct (Awang et al., 2018).
The discriminant validity analysis can be accessed in Table 3. The diagonal value of AVE's diagonal square root is higher than the value of its correlation (Awang et al., 2018). Therefore, discriminant validity is achieved.

\section{FINDING}

\section{The Direct Hypothesis Testing}

The formative analysis of the research model in Table 4 revealed that only three are statistically significant out of four relationships tested. When personal attitude

Table 2

The skewness, kurtosis, composite reliability (CR) and average variance extracted (AVE) result

\begin{tabular}{lccccc}
\hline \multicolumn{1}{c}{ Contructs } & Skewness & Kurtosis & CR & AVE & MSV \\
\hline Food safety knowledge (FS) & -0.582 & 0.222 & 0.860 & 0.605 & 0.196 \\
Personal attitude (AT) & -0.601 & 0.087 & 0.946 & 0.746 & 0.553 \\
Perceived social pressure (SP) & -0.12 & -0.51 & 0.921 & 0.75 & 0.592 \\
Perceived autonomy (AU) & -0.346 & 0.459 & 0.751 & 0.502 & 0.497 \\
Perceived green trust (GT) & 0.536 & 0.59 & 0.929 & 0.722 & 0.390 \\
Purchase intention (PI) & 0.459 & 0.075 & 0.922 & 0.856 & 0.592 \\
\hline
\end{tabular}


Table 3

Result of diagonal value and squared correlations of each construct

\begin{tabular}{|c|c|c|c|c|c|c|}
\hline Construct & FS & AT & SP & $\mathbf{A U}$ & GT & PI \\
\hline FS & 0.778 & & & & & \\
\hline AT & $0.173^{* *}$ & 0.864 & & & & \\
\hline SP & $0.221 * * *$ & $0.733 * * *$ & 0.866 & & & \\
\hline $\mathbf{A U}$ & $0.443 * * *$ & $0.556 * * *$ & $0.605^{* * *}$ & 0.709 & & \\
\hline GT & $0.383 * * *$ & $0.615 * * *$ & $0.538 * * *$ & $0.615 * * *$ & 0.850 & \\
\hline PI & $0.222 * * *$ & $0.744 * * *$ & $0.769 * * *$ & $0.705 * * *$ & $0.624 * * *$ & 0.925 \\
\hline
\end{tabular}

Note: $* * *=\mathrm{p}<0.001 ; * *=\mathrm{p}<0.010 *=\mathrm{p}<0.050$

Table 4

Result of a direct relationship tested

\begin{tabular}{lllccc}
\hline Direct relationship & & & Std.Est. & C.R. & p \\
\hline Personal attitude & $>$ & Purchase intention & .274 & 4.557 & $* * *$ \\
Perceived social pressure & $>$ & Purchase intention & .344 & 5.707 & $* * *$ \\
Perceived green trust & $>$ & Purchase intention & .095 & 1.754 & .079 \\
Perceived autonomy & $>$ & Purchase intention & .286 & 4.350 & $* * *$ \\
\hline
\end{tabular}

Note: $* * *=\mathrm{p}<0.001 ; * *=\mathrm{p}<0.010 *=\mathrm{p}<0.050$

goes up by 1, organic food purchase intention in a 'new normal' goes up by .274 with a $\mathrm{p}$-value score of 0.001 . As the p-value is less than 0.05 , the $\mathrm{H} 1$ is accepted. Besides, $\mathrm{H} 2$ of the study is also accepted as the p-value score of less than 0.05 . When perceived social pressure increase by 1 , organic food intention in a new normal increase by 344 .

However, there is no statistically significant between perceived green trust and organic food purchase intention in a new normal as the $\mathrm{p}$-value score is more than the p-value. Thus, H3 is not supported. Lastly, $\mathrm{H} 4$ is accepted because analyses indicate a p-value score of 0.05 and below when the perceived autonomy goes up by 1 , organic food's purchase intention in a new normal increase by 286 .

\section{The Hypothesis Testing of the Moderation Effect}

Moderation implied an interaction effect, where introducing a moderating variable changes the direction or magnitude of the relationship between two variables. Based on the finding in Table 4, H3 is not supported as there is no statistically significant relationship between perceived green trust and purchase intention of organic food in a new normal life. Thus no further moderating analysis is needed.

The summary outcome of the moderating analysis can be accessed in Table 5. Based on the finding, the only personal attitude had a moderating effect as the p-value of the interaction effect is less than 0.05 . Thus, H5 is supported (The positive effect of personal 
attitude and organic food purchase intention is stronger with food safety knowledge)

Meanwhile, food safety knowledge does not moderate the relationship between perceived social pressure and perceived autonomy toward purchase intention. The $\mathrm{p}$-value score on the interaction effect is more than 0.05. Therefore, H6 and H8 are not supported.
Examining the interaction plot of food safety knowledge on the relationship between personal attitude and organic food purchase intention showed an enhancing effect (Figure 3). At low personal attitude toward organic food, purchase intention is much higher for an individual with low food safety knowledge than those with high food safety knowledge. However, at moderate

Table 5

Summary of moderating analysis

\begin{tabular}{lcccc}
\hline & \multicolumn{3}{c}{ Interaction effect of Moderating Analysis } \\
\hline Personal attitude & $\underline{\text { Coeff. }}$ & $\underline{\text { LLCI }}$ & $\underline{\text { ULCI }}$ & $\underline{\mathrm{p} \text {-value }}$ \\
Perceived social pressure & 0.014 & 0.004 & 0.024 & 0.005 \\
& $\underline{\text { Coeff. }}$ & $\underline{\text { LLCI }}$ & $\underline{\text { ULCI }}$ & $\underline{\mathrm{p} \text {-value }}$ \\
Perceived autonomy & 0.005 & -0.008 & 0.018 & $.422^{*}$ \\
& $\underline{\text { Coeff. }}$ & $\underline{\text { LLCI }}$ & $\underline{\text { ULCI }}$ & $\underline{\mathrm{p} \text {-value }}$ \\
\hline
\end{tabular}

Note: *The p-value of interaction effect is more than 0.05 , thus no moderation effect

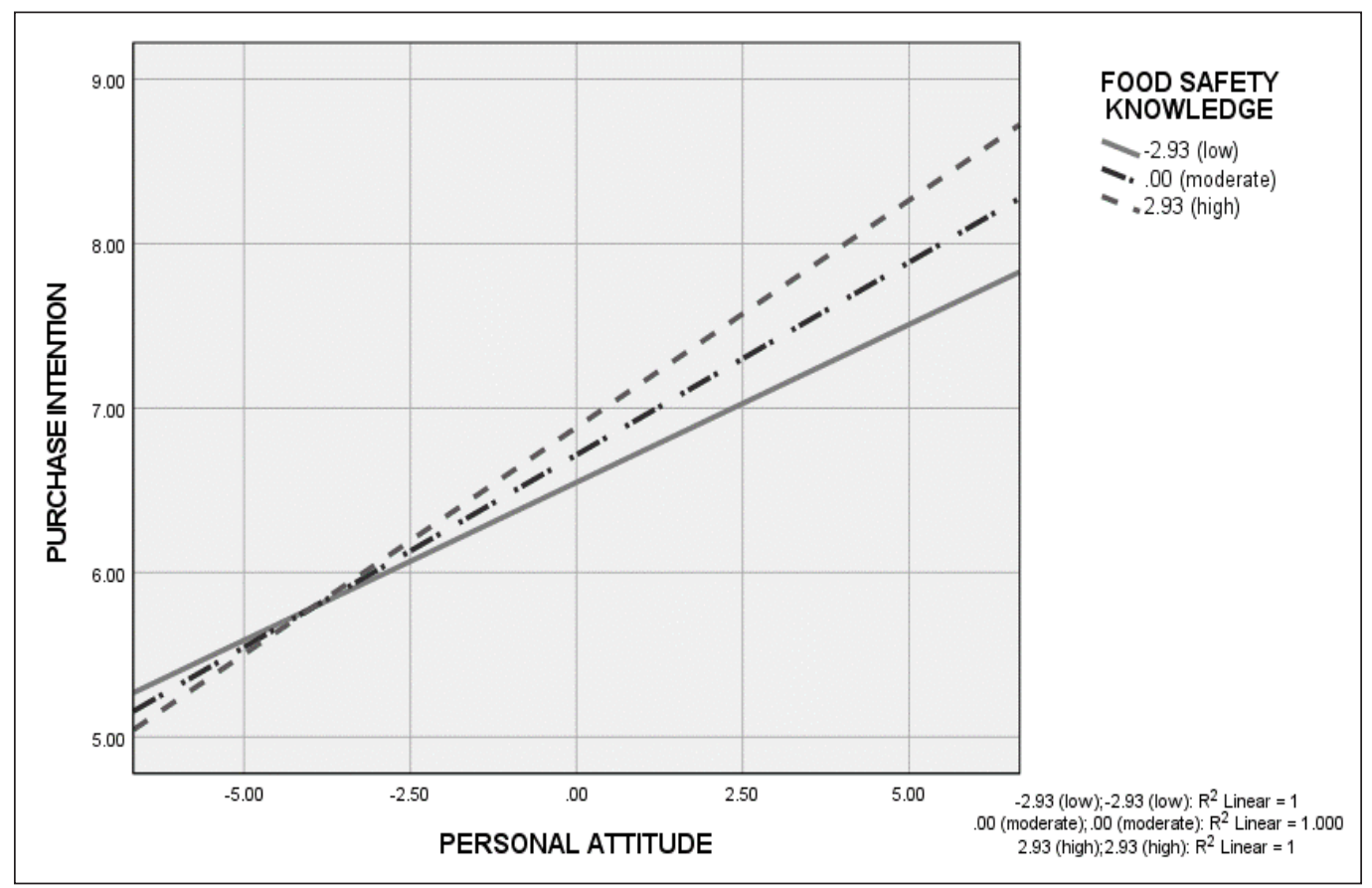

Figure 3. Interaction plot of moderating analysis between intention and personal attitude 
and high personal attitudes, the purchase intention increases according to the level of food safety knowledge. Furthermore, a high level of food safety knowledge increases organic food's purchase intention at a high personal attitude. Thus, when the individual has a positive high personal attitude toward organic food, the purchase intention similarly tends to be higher if they have high food safety knowledge.

\section{DISCUSSION AND CONCLUSION}

Based on the analyses executed, organic food purchase intention was significant statistically towards three variables inspected: personal attitudes, perceived social pressure, and perceived autonomy in a new normal life of COVID-19. On the other hand, perceived green trust is not significant towards organic food purchase intention statistically in a new normal life of COVID-19. However, food safety knowledge was found to moderate personal attitude and organic food purchase significantly.

The significant influence of personal attitudes on organic purchase intention in a new normal life (H1) theoretically clarifies how a positive attitude on organic food impacts the purchase intention in a new normal life. According to Ajzen (1991), the desire to carry out a particular action may increase with a positive attitude towards a certain action. Besides, another researcher also supported that the purchase intention of organic food products is significantly impacted by consumer's positive attitudes (Bai et al., 2019; Ham et al., 2018; Latip et al., 2020b). The findings explained that individuals' aptitude to purchase organic food is influenced by the strength of the individuals' control factors. Moreover, due to the pandemic COVID-19 individual perception and concern about the infection theoretically shape their attitude on minimising the potential risk of infection by consuming healthy food and ensuring maximum body health. It is supported by a recent study as consumers are undeniably concerned about their health (Latip et al., 2020b). Moreover, a consumer may emphasise more belief in personal judgment than social influence as it builds up selfconfidence and personal belief.

Furthermore, the significant influence of perceived social pressure on organic purchase intention in a new normal life (H2) hypothetically clarifies how social pressure from surrounding govern the organic purchase intention in a new normal life. According to Latip et al. (2020b), the social weight that individuals encounter may influence their decision whether to perform or not to perform specific behaviour in mind. The relationship between social pressure and intention to purchase organic food becomes stronger when both factors, which are internal (individuals) and external (social pressure), are positive towards particular matters. Indeed, as COVID-19 affects the whole world, the pressure to comply with a social norm and expectation to break the chain of infection is even sturdier. The impact is even stronger in a collectivist country. 
The significant influence of perceived autonomy towards organic food purchase intention in a new normal life (H4) supported the finding of a previous scholar by Bai et al. (2019), Ham et al. (2018), and Lian (2017), which found a significant relationship between perceived behavioural control (autonomy) and intention to purchase organic food. The inclination for individuals to have the intention to purchase organic food influenced by how high is their behaviour control. In the new normal life of COVID-19, few restrictions have to be obeyed by the consumer as regulated by the government. Therefore, it theoretically justifies the significant relationship between the more autonomy individuals perceived and the stronger intention to perform a specific action.

Nonetheless, there was no significant influence between perceived green trust and intention to purchase organic food in a new normal life (H3). It is supported by the previous scholar Latip et al. (2021), as green trust does not influence organic food purchase intention. Indeed, trustworthiness does not influence the purchase attitude of organic food (Bai et al., 2019). Furthermore, the trust in the greener aspect of organic food does not significantly influence consumers when the resources are limited. However, due to the pandemic COVID-19, some resources may be limited, and scarcity of particular organic food. Besides, in a critical time of health crisis like pandemic COVID-19, food safety is more critical than a real green aspect. Thus, green trust in organic food is not an essential issue that influences the consumer purchase decision.
On the other hand, the study found that food safety knowledge has a significant moderating effect between personal attitude and organic food purchase intention (H5). Knowledge leads to stronger individuals' beliefs and contributes to buying organic food products among consumers during the COVID-19 pandemic. Purchase intention and individuals' perception of the products may be shifted when they possess adequate knowledge about the product (Jaiswal \& Kant, 2018; Nguyen et al., 2019). Besides, consumers' health knowledge has increased their tendency to choose organic foods, especially during pandemic COVID-19 (Latip et al., 2020b). As the attitude and personal belief on organic food safety exist, the relationship is sturdier with food safety knowledge. Meanwhile, food safety knowledge does not moderate the relationship between perceived social pressure and purchase intention because of the contradiction of external forces (norm) and personal knowledge. Thereby potentially explaining the finding attained.

\section{Limitation and Future Research}

Although the study's findings have highlighted the insightful significance, the study encountered a few limitations. The first limitation is that the study was only conducted on a particular area intended to be measured. On the grounds, the whole world is still facing a current pandemic situation. This study fully utilises the online survey to generate the samples to comply with social distancing directives. The pandemic COVID-19 has abrupted the lifestyle 
changes over social distancing and concern about health, affecting social life and economics (Latip et al., 2020b). Besides, this study applied the quantitative approach, which restricted information gathering only based on answers and question options created by researchers. As a result, there is some phenomenon unable to be measured by figures. Hence, future researchers need to test different constructs to broaden the study's findings on organic food consumer behaviours in a new normal life. Future studies may consider applying the mixedmethod approach, providing more in-depth information on the construct examination. Besides, elements of communication, greenwashing and diet habits should be incorporated.

\section{Recommendation and Implication}

The study is anticipated to add an advanced dimension related to organic food studies. It is investigated in a new normal life of pandemic COVID-19, a very peculiar situation for the world. Besides, there is a need for the study to expedite, especially for Asian countries, which the organic food industry is still at the initial stage as the scarcity of information on green food purchase behaviour and consumer perception leads to market attractiveness disruption arises concerning business risk, profitability and sustainability aspects (Latip et al., 2020b). Thus, this study highlighted several crucial findings that may differ from previous research as the construct is also contra. During this post MCO period, the purchasing power of consumers may decrease as a continuous trend expected based on the retrenchment figure at the end of March, which involved about 70\% from the B40 and 28\% from M40 (Kana, 2020).

Moreover, the study further extends the theory of planned behaviour by including related predictors that specifically measure green consumerism, namely perceived green trust and food safety knowledge. The original predictors of attitude, subjective norm, and perceived behavioural control were included in the study, which referred to personal attitude, perceived social pressure and perceived autonomy that carry the same underline factor as supported by (Latip et al., 2020a). The expanded model will enlighten green consumerism study, especially in Asia, as it is relatively new and more studies are needed to understand the consumer perspective better.

The study is useful for the industry, comprehending the changes that new normal brought towards their business and revamping their marketing strategy to align with the current market situation. The finding also calls for the industry to further educate and publicise the food safety knowledge aspect of organic food to consumers to generate public interest and awareness, as the food safety knowledge significantly moderate consumer attitude toward purchase intention. Moreover, the governmentrelated body such as the Department of Agriculture should collaborate with other related agriculture-based bodies and organic food producers to disseminate the benefits of consuming organic food and highlight organic food's safety and health features to 
the public. For example, a poster or other form of communication can be displayed through a campaign or other marketing initiatives to increase consumer awareness and receptivity toward the organic food product at the grocery store. When consumer awareness and familiarity with organic food increases, it somehow influences consumers to purchase the product, increase the national GDP and open for a massive export opportunity as the myOrganic of Malaysia scheme is recognised globally. In return, the consumer will have better access to a variety of organic food products free from pesticides and safe to be consumed.

\section{ACKNOWLEDGEMENTS}

This research is supported by Universiti Teknologi MARA and UNIRAZAK Postgraduate Development Program.

\section{REFERENCES}

Adawiyah, R., Najib, M., \& Ali, M. M. (2021). Information effect on organic vegetable purchase interest through consumer preferences and awareness. Journal of Asian Finance, Economics and Business, 8(2), 1055-1062. https://doi. org/10.13106/jafeb.2021.vol8.no2.1055

Aertsens, J., Verbeke, W., Mondelaers, K., \& van Huylenbroeck, G. (2009). Personal determinants of organic food consumption: A review. British Food Journal, 111(10), 1140-1167. https://doi. org/10.1108/00070700910992961

Awang, Z., Hui, L. S., \& Zainudin, N. F. S. (2018). Pendekatan mudah SEM - Structural equation modelling. MPWS Rich Resources Sdn. Bhd.

Babulal, V., \& Krishnan, D. B. (2020, November). Experts: 2021 Budget does not address challenges facing agriculture sector. New Straits Times.
Bai, L., Wang, M., \& Gong, S. (2019). Understanding the antecedents of organic food purchases: The important roles of beliefs, subjective norms, and identity expressiveness. Sustainability (Switzerland), 11(11), 3045-3063. https://doi. org/10.3390/su11113045

Baktash, L., \& Talib, M. A. (2019). Green marketing strategies: Exploring intrinsic and extrinsic factors towards green customers' loyalty. Quality - Access to Success, 20(168), 127-134.

Briggs, A. R., Coleman, M., \& Morrison, M. (2012). Research methods in educational leadership and management. SAGE Publications.

Chaturvedi, A., Chand, M. R., \& Rahman, M. (2021). Impact of the COVID-19 on consumer behavior towards organic food in India. In Predictive and preventive measures for Covid-19 pandemic (pp. 127-148). Springer Nature Singapore Pte Ltd. https://doi.org/10.1007/978-981-33-4236-1_8

Correa, C., Junior, S., \& Da Silva, D. (2017). The social control exerted by advertising: A study on the perception of greenwashing in green products at retail. British Journal of Education, Society \& Behavioural Science, 19(2), 1-9. https://doi. org/10.9734/bjesbs/2017/29819

Eichhorn, B. R. (2014). Common method variance techniques. Midwest SAS Users Group, 1-11.

Euromonitor International. (2017). Certified organic: Opportunities in food and beverages. Euromonitor, 66. https://www.euromonitor.com/ certified-organic-opportunities-in-food-andbeverages/report

Fraser, D. (2001). The "New Perception" of animal agriculture: Legless cows, featherless chickens, and a need for genuine analysis. Journal of Animal Science, 79(3), 634-641. https://doi. org/10.2527/2001.793634x

Giampietri, E., Verneau, F., Del Giudice, T., Carfora, V., \& Finco, A. (2018). A theory of planned behaviour perspective for investigating the 
role of trust in consumer purchasing decision related to short food supply chains. Food Quality and Preference, 64, 160-166. https://doi. org/10.1016/j.foodqual.2017.09.012

Ha, T. M., Shakur, S., \& Pham Do, K. H. (2018). Consumer concern about food safety in Hanoi,Vietnam. Food Control, 98, 238-244. https://doi.org/10.1016/j.foodcont.2018.11.031

Hair, J. F., Black, W. C., Babin, B. J., \& Anderson, R. E. (2010). Multivariate data analysis: A global perspective (Global Edi). Pearson Education.

Hair, J. F., Hult, G. T. M., Ringle, C. M., \& Sarstedt, M. (2017). A primer on Partial Least Squares Structural Equation Modeling (PLS-SEM) (2nd ed.). SAGE Publications.

Ham, M., Pap, A., \& Stanic, M. (2018). What drives organic food purchasing? Evidence from Croatia. British Food Journal, 120(4), 734-748. https:// doi.org/10.1108/eb011783

Hassen, T. B., El Bilali, H., \& Allahyari, M. S. (2020). Impact of covid-19 on food behavior and consumption in Qatar. Sustainability, 12, 6973. https://doi.org/10.3390/su12176973

Hayes, A. F. (2013). Introduction to mediation, moderation and conditional process analysis: A regression-based approach. Guilford Press.

Jaafar, N. A. A., Sulaiman, N., Sabran, M. R., \& Badari, S. A. Z. (2020). A systematic review of 10 years of empirical studies on organic food consumption among Malaysian consumers. Malaysian Journal of Consumer and Family Economics, 25(S1), 111-134.

Jaiswal, D., \& Kant, R. (2018). Green purchasing behaviour: A conceptual framework and empirical investigation of Indian consumers. Journal of Retailing and Consumer Services, 41(December 2017), 60-69. https://doi. org/10.1016/j.jretconser.2017.11.008

Junior, S. B., Martínez, M. P., Correa, C. M., Moura-Leite, R. C., \& Da Silva, D. (2019).
Greenwashing effect, attitudes, and beliefs in green consumption. RAUSP Management Journal, 54(2), 226-241. https://doi.org/10.1108/ RAUSP-08-2018-0070

Kana, G. (2020, May). Dent in Malaysians'spending. The Star Online.

Latip, M. S. A., Newaz, F. T., Latip, S. N. N. A., May, R. Y. Y., \& Rahman, A. E. A. (2021). The sustainable purchase intention in a new normal of COVID-19: An empirical study in Malaysia. Journal of Asian Finance Economics and Business, 8(5), 951-959. https://doi. org/10.13106/jafeb.2021.vol8.no5.0951

Latip, M. S. A., Newaz, F. T., Noh, I., \& Mohamad, A. M. (2020a).Individual green consideration model: A conceptual study. International Journal of Management, 11(7), 849-858. https://doi. org/10.34218/IJM.11.7.2020.075

Latip, M. S. A., Newaz, F. T., Ramasamy, R., Tumin, S. A., \& Noh, I. (2020b). How do food safety knowledge and trust affect individual's green considerations during the COVID-19 pandemic in Malaysia? Malaysian Journal of Consumer and Family Economics, 24, 261-285.

Lian, S. B. (2017). What motivates consumers to purchase organic food in Malaysia? Asian Social Science, 13(9), 100. https://doi.org/10.5539/ass. v13n9p100

Lian, S. B., \& Yoong, L. C. (2019). Assessing the young consumers' motives and purchase behavior for organic food: An empirical evidence from a developing nation. International Journal of Academic Research in Business and Social Sciences, 9(1), 69-87. https://doi.org/10.6007/ ijarbss/v9-i1/5364

Madden, T. J., Ellen, P. S., \& Ajzen, I. (1992). A Comparison of the Theory of Planned Behavior and the Theory of Reasoned Action. Personality and Social Psychology Bulletin, 18(1), 3-9. https://doi.org/10.1177/0146167292181001 
Nguyen, H. V., Nguyen, N., Nguyen, B. K., Lobo, A., \& Vu, P. A. (2019). Organic food purchases in an emerging market: The influence of consumers' personal factors and green marketing practices of food stores. International Journal of Environmental Research and Public Health, 16(6), 1037. https://doi.org/10.3390/ ijerph16061037

Prentice, C., Chen, J., \& Wang, X. (2019). The influence of product and personal attributes on organic food marketing. Journal of Retailing and Consumer Services, 46, 70-78. https://doi. org/10.1016/j.jretconser.2017.10.020

Putten, Y. Y. A., \& Nair, P. B. (2019). Green food product purchase intention: Factors influencing Malaysian consumers. Pertanika Journal of Social Science and Humanities, 27(2), 11311144 .

Qi, X., \& Ploeger, A. (2019). Explaining consumers' intentions towards purchasing green food in Qingdao, China: The amendment and extension of the theory of planned behavior. Appetite, 133, 414-422. https://doi.org/10.1016/j. appet.2018.12.004

Qi, X., Yu, H., \& Ploeger, A. (2020). Exploring influential factors including COVID-19 on green food purchase intentions and the intentionbehaviour gap: A qualitative study among consumers in a Chinese context. International Journal of Environmental Research and Public Health, 17(19), 1-22. https://doi.org/10.3390/ ijerph17197106

Rieger, J., Kuhlgatz, C., \& Anders, S. (2016). Food scandals, media attention and habit persistence among desensitised meat consumers. Food Policy, 64, 82-92. https://doi.org/10.1016/j. foodpol.2016.09.005

Sajed, A. N. N., \& Amgain, K. (2020). Corona virus disease (COVID-19) outbreak and the strategy for prevention. Europasian Journal of Medical Sciences, 2(1), 1-4.
Scalco, A., Noventa, S., Sartori, R., \& Ceschi, A. (2017). Predicting organic food consumption: A meta-analytic structural equation model based on the theory of planned behavior. Appetite, 112, 235-248. https://doi.org/10.1016/j. appet.2017.02.007

Shaw, A. (2004). Discourses of risk in lay accounts of microbiological safety and BSE: A qualitative interview study. Health Risk \& Society, 6, 151-171. https://doi.org/10.1080/1369857042000219779

Somasundram, C., Razali, Z., \& Santhirasegaram, V. (2016). A review on organic food production in Malaysia. Horticulturae, 2(12), 1-5. https://doi. org/10.3390/horticulturae2030012

Teng, P. K., Rezai, G., Mohamed, Z., \& Shamsudin, M. N. (2011). Consumers' intention to purchase green foods in Malaysia. International Conference on Innovation, Management and Service, 14, 112-118.

Wang, J., Shen, M., \& Gao, Z. (2018). Research on the irrational behavior of consumers' safe consumption and its influencing factors. International Journal of Environmental Research and Public Health, 15(12), 2764-2777. https:// doi.org/10.3390/ijerph15122764

Xie, B., Wang, L., Yang, H., Wang, Y., \& Zhang, M. (2015). Consumer perceptions and attitudes of organic food products in eastern China. British Food Journal, 117(3), 1105-1121. https://doi. org/10.1108/BFJ-09-2013-0255

Xie, X., Huang, L., Li, J., \& Zhu, H. (2020). Generational differences in perceptions of food health/risk and attitudes toward organic food and game meat: The case of the COVID-19 crisis in China. In International Journal of Environmental Research and Public Health, 17(9), 3148-3165. https://doi.org/10.3390/ijerph17093148

Yzer, M. (2017). Theory of reasoned action and theory of planned behavior. The International Encyclopedia of Media Effects, 1-7. https://doi. org/10.1002/9781118783764.wbieme0075 
